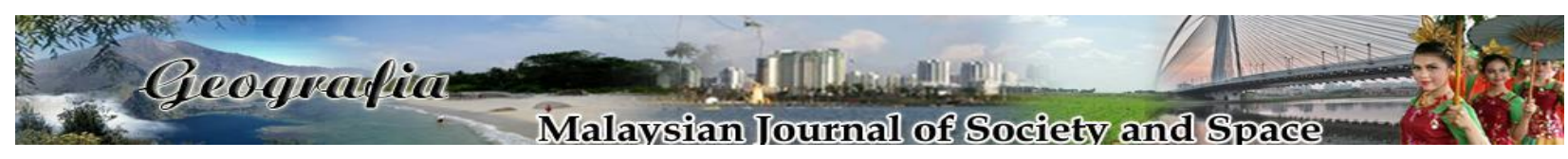

\title{
Critical determinants on flooding: Perception analysis with reference to Kelani River in Sri Lanka
}

\author{
N.C. Wickramaarachchi, B.H.N. Perera \\ Department of Estate Management and Valuation, University of Sri Jayewardenepura, Sri Lanka \\ Correspondence: N.C. Wickramaarachchi (email: nishani@sjp.ac.lk)
}

Received: 17 May 2021; Accepted: 19 July 2021; Published: 27 August 2021

\begin{abstract}
Flooding receives the priority among the natural disasters in the world. During the past decades, several places in Sri Lanka also were exposed to severe flooding causing massive damages to human lives and properties. A famous place for recurrent flooding in the country finds by the sides of one major river called 'Kelani', and continuous damages reported in Kaduwela Municipal Council limits, where Kelani River flows through. Documentary records show the average annual estimated cost for damages is over USD $\$ 50,000$ /- during the past years in this area. This is an alarming figure to continue and there is inadequate evidence on research, identifying the factors contributing on recurrent flooding. This research aims to analyze the determinants of flooding based on Kelani River, in Kaduwela Municipal Council limits, focusing on both natural and manmade factors. Sixty families through systematic random sampling, were selected representing the most vulnerable areas, to collect data through a structured questionnaire on ten variables and indepth interviews were conducted with five selected experts. The study followed both quantitative and qualitative analysis respectively, descriptive analysis and qualitative method of Analytic Hierarchy Process method used to identify most influencing factors. The findings emphasized that man-made flood causative factors were the most responsible factors for the flood vulnerability in the area even with one-two day's rain. Most significantly, non- availability of a proper drainage system and violation of rules and regulations are the most acute factors. Findings emphasize the necessity to implement proper measures to minimize the flood risk of the area.
\end{abstract}

Keywords: Flood determinants, flood risk, man-made factors, natural disasters, natural factors

\section{Introduction}

Among the different types of natural disasters, flooding is one of the recurrently occurring climaterelated disaster. It is very natural and simple to understand that the floods are mostly caused due to frequent and heavy rainfall. However, it may occur due to sudden melting snow coupled with considerably low ability or even inability to retain water in an area (Svetlana et al., 2015). The 
frequency and consequences of severe flood events have increased in recent decades (Bouwer et al., 2007; Kron, 2009). The global annual economic losses caused by floods during $20^{\text {th }}$ century was accounted to $3.0 \times 10^{10}$ USD which was in another words one-third of total economic losses caused by all types of natural disasters (Shao et al., 2019). It is also projected that the losses and damages due to floods will increase due to expanding exposure of assets and increasing population. Alfieri et al. (2017) discovered a considerable rise in flood risk due to the combination of the future flood hazard and information on global exposure and vulnerability in most regions of the world. In that context, flood risk has already become a major threat to most of the continents.

Sri Lanka is very rich with many water bodies including 103 rivers which are valuable gift from the Mother Nature (Surasinghe et al., 2020). However, sometimes those resources are acting against to the people because of natural and manmade causes. Mainly heavy floods during the rainy seasons make many villages and cities vulnerable in the country. Considering the local experiences during the recent decades, it was identified that the most frequent natural disaster observed in Sri Lanka was floods, followed by strong wind, landslides and cyclones. The recent evidence recorded in 2016 that flood and landslides were affected for 24 districts which was impacting about 493,319 people of 124,398 families while death of 93 people 33 injured people and 117 were missing (Ministry of Disaster Management, 2016). Also, in 2017 about 200,050 people in eight districts of Sri Lanka were impoverished of their lives and nearly 2,093 houses were completely damaged, and 11,056 houses were partially damaged due to the flood and landslide disasters (Disaster Management Centre, 2017). Accordingly, almost a huge number of people, families and properties has been damaged. On the other hand, a large amount of government funds is using to get the damages recovered. This is may be to replace the homes of people or may be to cover the loss of deaths. Therefore, it is worth to identify the main determinants of floods thus the precautions can be taken.

One of such vulnerable areas to recurrent flooding, is the two sides of Kelani River in Kaduwela Municipal Council area. The recent flood which was occurred in 2016 was recorded as critical in this area after the major flood in 1989. The damages of 2016 flood were elevated because of inundation in longer time caused by the irregular developments within Kelani River flood plain area (Hettiarachchi, 2020). Meanwhile Kaduwela Municipal Council documentary records show the annual average estimated cost of damages is over Rs.10, 000, 000 during the past years. On average 10,000 people, 3000 families and around 300 small and medium business are yearly reported as affected and damaged. The figures emphasize the alarming nature of the issue and there is no evidence on findings to identify the factors that are contributing to this recurrent flooding in detail. Screening through the literature it was noted that many scholars' views as flood is a result of extreme weather conditions such as heavy rainfalls whilst, some arguments are there that it is not merely based on natural factors, but in some cases may be human activities also contributing.

Despite these causes, flooding is a matter of changing from location to location thus a comprehensive analyze is inevitable. In addition, researchers find that the heavy rainfall will increase over the coming decades and will lead to rapid flooding in the country (Farley et al., 2017). Hence, it is vital to identify the determinants contribute to flooding in the particular area which is not discussed at a length yet. Therefore, the study aims to analyze the critical flood causing factors associated with the flood risk in Kelani River in Sri Lanka from the point of effected parties and at the same time using the expert's view. 


\section{Literature review}

\section{Natural disasters}

A disaster is an occurrence disrupting the normal conditions of existence and causing a level of suffering that exceeds the capacity of adjustment of the affected community (WHO/EHA, 2002). This can be caused by nature or by human influence. Natural disasters are mostly originated through environmental changes. As stated by Zhou et al. (2017), natural disasters refer to the natural processes that occur in the ecosystem, which can lead to the loss of stability of the socialeconomic system, and serious imbalance between supply and demand of social resources. These natural disasters can be divided into six categories: geological (e.g. landslides, earthquakes, tsunami and volcanic activity), climatological (e.g. drought, wildfire and extreme temperatures), hydrological (e.g. floods and avalanches), biological (insect/animal plagues and disease epidemics), meteorological (e.g. storms/wave surges and cyclones) and extraterrestrial (e.g. impact and space weather) (EM-DAT, 2009). Its damages can be aggravated due to the human inappropriate influence.

In 2019, EM-DAT reported 396 natural disasters that caused 11,755 deaths, 95 million of affected people and 103 billion US\$ in economic loss across the world (CRED, 2020). It is identified that with increase population and infrastructure which were exposure to the world, claimed for the economic losses and lives were growing rapidly comparing to the past incidents (Brauch, 2003; GRID-Arendal, 2006; Stoffel et al., 2010; Hoeppe, 2016; JICA, 2017). According to EM-DAT, since 2006, the number of hydrological disasters has continued to account for the highest proportion of natural disasters, with $51.8 \%$ in 2016 (an average of $50.5 \%$ from 2006 to 2015) (CRED, 2020). Consequently, as a hydrological disaster, $99.7 \%$ of people suffered from floods in 2016 and the total death occurrences of flooding were accounted as $17 \%$.

\section{Flooding}

Flood and water logging have been one major threat for human survival since the ancient times (Shao et al., 2019). As explained by Khan et al. (2011), floods are among most devastating and recurring natural hazards which impacts largely on human lives and economies of the world. Erena and Worku (2018) stated that "Flood is one of the leading natural hazards worldwide both in terms of the frequency of occurrence and the resulting damages to human lives, the environment, and economic assets". Floods can cause widespread devastation, resulting in loss of life and damages to personal property and critical public health infrastructure. During 1998-2017, floods affected more than 2 billion people worldwide (WHO, 2021). The frequency and consequences of severe flood events have rapidly increased during recent decades (Bouwer et al., 2007; Kron, 2009). The intensification of hydrological cycle due to global warming has increased the exposure to future floods and its impact on economy and health of the countries (Alfieri et al., 2017).

As per World Health Organization, flood can be classified in to three types: flash floods, river floods (mostly seasonal) and costal floods associated with tropical cyclones, tsunami and storm surges. Risk of such floods may increase due to a range of changes in the use of land, which induce changes of hydrological systems (Svetlana et al., 2015). The number of people affected by flood were growing each year and the majority are from developing countries. As a developing third world country, Sri Lanka has experienced numerous types of natural disasters during recent 
decades. Out of all these natural disasters floods are the most common and recurrent type of disaster that has caused a huge threat on human lives and properties. The extreme flood event occurred in 2016 affected about 0.5 million people and caused LKR108,515,209,350 cost of flood damages (Ministry of Irrigation and Water Resources Management, 2018). Further, it was recorded that, due to floods and landslides be fallen in May 2017, nearly two hundred and fifty people in eight districts of the island were deprived of their lives and nearly 80 people have disappeared meanwhile 2,093 houses were completely damaged, and 11,056 houses were partially damaged which caused for the huge impact to the country (Disaster Management Centre, 2017).

\section{Factors causing for flood risk}

Many researchers and organizations identified flood as a major problem that exists in the world and studied on factors which contribute to increase its severity and damages. There are many determinants caused to the flood risk. Those can be categorized in to physical, social and environmental etc. Some physical factors are the topography, soil type and the soil moisture, slope of the lands etc. Under social aspect, the attitudes of the people, activities of the different organizations, encroachments, sand mining in river valleys and political influence can direct to increase flood risk. The changes of the climatic factors such as rainfall pattern and wind velocity etc. can be identified as environmental factors. Those factors can be broadly observed as natural and man-made factors. Even though flooding is considered as a natural disaster its severity and frequency can also be aggravated due to direct and indirect human involvement.

According to the above categorization scholars have identified a range of man-made factors that cause floods or even increase damages. As per the literature multiple man-made factors can be identified such as urbanization (Svetlana et al., 2015; Erena \& Worku, 2018; Cirella et al., 2019), encroachments (Erena \& Worku, 2018), increasing population (Svetlana et al., 2015; Cirella et al., 2019), improper land use changes (Al-Juaidi et al., 2018; Erena \& Worku, 2018; Cirella et al., 2019), deforestation (Svetlana et al., 2015), blockage of drainages (Cirella et al., 2019), improper waste disposal (Cirella et al., 2019; Erena \& Worku, 2018; Ijaz et al.,2021 ), reduction of wetlands (Svetlana, et al., 2015) etc. On the other hand natural factors such as heavy rainfall (Erena \& Worku, 2018; Cirella et al., 2019; Al-Juaidi et al., 2018), topology (Erena \& Worku, 2018; Al-Juaidi et al., 2018), soil type (Al-Juaidi et al., 2018; Cirella et al., 2019), wind (Hadipour et al., 2020) etc. are also cause to increase flood risk at a greater extent.

As per the empirical findings of different scholars were identified that most responsible flood causing factors can be different from place to place and time to time. Erena and Worku (2018) through their study in Ethiopia found that the major determinants as intense rainfall, encroachment to riverbanks, topography, waste management factor, land use change and urban expansion, institutional factor, aggravating factors, stream orders, texture and stream frequency. Cirella et al. (2019) in Benin city, Nigeria identified that heavy rainfall as the highest flood causing factor while blockage of drainages, improper waste disposal, land nature, soil texture, slums, uncontrolled developments and overpopulation being some other major factors. An experience from Pakistan shows that heavy rain and the mixed water with the openly dumped solid waste occurring through improper waste disposal caused for flood (Ijaz et al., 2021). However, it has been commonly accepted that urbanization and population growth make a greater influence over flood risk (Svetlana et al., 2015; Cirella et al., 2019; Erena \& Worku, 2018). Empirical findings about flooding in different countries and cities identified those responsible factors to flooding. It can be differing from place to place. Identifying the causes are very important to the relevant 
authorities to overcome or mitigate the problem. It can be reduced millions of monetary resources are spent on recoveries and compensations by saving the economy of the country. With that background, this study attempts to identify the flood causative factors in Kelani River area in Sri Lanka which is significant from previous studies.

\section{Method and study area}

\section{Study area}

The study was primarily carried out in Kaduwela Municipal Council (MC) limits which belongs to the administrative district of Colombo, Western Province, Sri Lanka (Figure 1). The Kelani is one of Sri Lanka's main river systems. It is ranked seventh in terms of the size of its watershed (2, $340 \mathrm{~km}^{2}$ ) following through the Kaduwela MC limits in Sri Lanka (Hettiarachchi, 2020). Due to ample rainfall in the catchment, it ranks third in terms of water resources (4, $225 \mathrm{MCM}$ of average annual yield). The catchment's average annual rainfall ranges from 5,700 $\mathrm{mm}$ in the upper basin to $2,300 \mathrm{~mm}$ in the lower basin. The river takes wider in this area because of the flat terrain. The Kelani River's lower basin is prone to heavy flooding due to heavy rainfall and the steep terrain of the upper catchment. Therefore, during the rainy season or with sudden heavy rains it is noted that some parts of this area usually affected by floods. The environmental, economic, and social impacts due to the hazardous flood event usually creates huge losses and costs in the area.

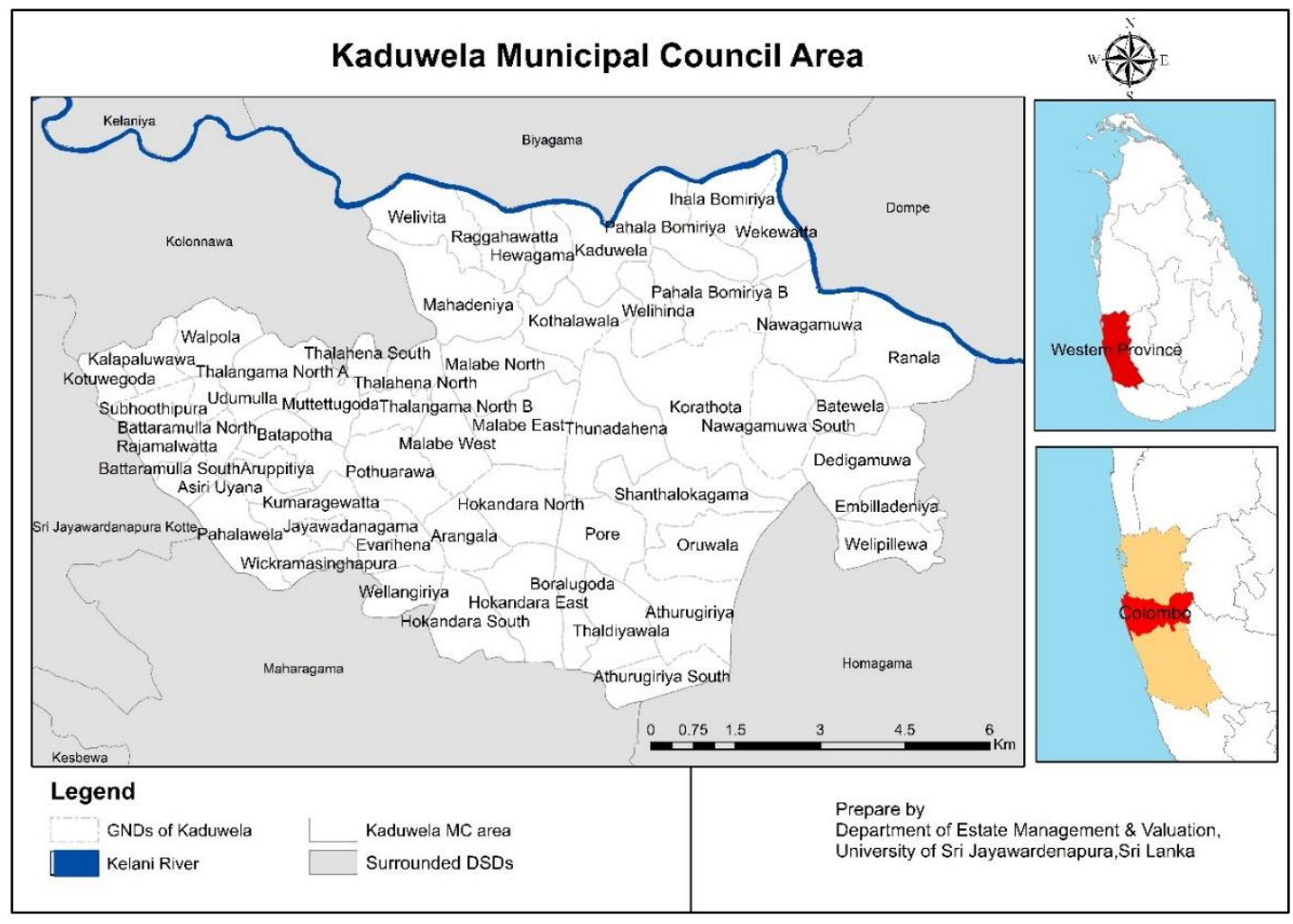

Source: Survey data, 2020

Figure 1. Location of the study area. 


\section{Population and sample}

The population of this study are two types as the residents living in the flood risk areas in Kaduwela $\mathrm{MC}$ and few selected experts from the area. As per the discussions held with the municipal council officers it was identified that there are 10 Grama Niladari Divisions (village level administrative unit) that are normally vulnerable for flood. Out of the 10 divisions, the study selected four major flood risk Grama Niladari (GN) Divisions; Kaduwela, Wekkawatta, Ranala and Nawagamuwa for the survey and 60 families were chosen as the sample on systematic random sampling basis who are living in these four GN divisions. In addition, five experts such as Grama Niladari (the administrative officer at village level), a member from Municipal Council (disaster management section), President of the Trade Union in the Kaduwela city area and two leaders from village level societies who are having more than 30 years living experience in this area were selected for indepth interviews.

\section{Data collection method}

Both primary and secondary data were used in the research and primary data collection was done using a five-point Likert scale questionnaire and through the scheduled interviews. The questionnaire survey was used to collect primary data on 10 flood causing determinants identified through literature and confirmed as suited to this area under two categorization as natural and manmade factors. Perceptions on these 10 factors were collected from 60 families whereas the interviews were conducted to collect the perceptions and views over flood causing determinants from experts. Further, through observations several other necessary data such as the distance to Kaleni River from settlements, number of encroachments, the blockages in the river and the condition of drainage etc., were justified. The questionnaire was developed mainly focusing on natural factors and man-made factors that cause to increase flood risk according to available literature. Variables under each factor were taken from previously validated instruments in literature, observations in the field and the factors which expressed by the affected people as follows. Table 1 shows the variables identified for this study.

Table 1. Identification of variables based on literature.

\begin{tabular}{ccc}
\hline Category & Variable & Sources of literature \\
\hline \multirow{4}{*}{ Natural factors } & Rainfall & Erena \& Worku (2018); Cirella et al. (2019) \\
& Wind & Hadipour et al. (2020) \\
& Land & Erena \& Worku (2018); Cirella et al. (2019) \\
& Soil condition & Cirella et al. (2019) \\
& River characteristics & Erena \& Worku (2018) \\
\hline \multirow{2}{*}{$\begin{array}{c}\text { Man-made } \\
\text { factors }\end{array}$} & Population increment & Chan (1997); Erena \& Worku (2018); Cirella et al. (2019) \\
& Land use change & Chan (1997); Erena \& Worku (2018); Cirella et al. (2019) \\
& Improper waste disposal & Erena \& Worku (2018); Cirella et al. (2019); Ijaz et al. \\
& Lack of drainage system & (2021) \\
Violating regulations & Erena \& Worku (2018); Cirella et al. (2019) \\
& Cirella et al. (2019) \\
\hline
\end{tabular}

Source: Author Constructed, 2020 


\section{Data analysis method}

Data were analyzed using both quantitative and qualitative approaches to achieve the objective of the research. The data collected through the questionnaire from residents were analyzed using descriptive statistics. Furthermore, the Analytic Hierarchy Process (AHP) may be used to integrate subjective criteria, both quantitative and qualitative. It was considering as most convenient method for decision making. Therefore, in the study, the perceptions of the experts obtained through interviews were analyzed under a qualitative approach by using AHP to measure experts' priorities about flood causing determinants through assigning subjective value.

\section{Results and discussion}

Descriptive analysis of the study mainly describes the locational characteristics of the respondents and the flood causing factors as follows;

\section{Proximity to Kelani River}

According to Figure 2, $60 \%$ of the respondents are living below 100m distance from the Kelani River. This demonstrates that majority of the residential units i.e. $90 \%$ were located very close proximity to the river. It is noted that the properties that are significantly close to the riverbank find a greater risk for floods. As per the Land Manual of Sri Lanka (Land Commissioner Department) it declares the extent of reservations on the sides of the rivers. Accordingly for a river with a width of more than 15 meters should allow three chains (60 meters) from each river bank as the reservation. Hence the results according to Figure 2 indicates that majority of the people have violated this rule and settled within the preservation zone area. Another $33 \%$ were in $100 \mathrm{~m}$ to $500 \mathrm{~m}$ distance. Only $7 \%$ were located more than $500 \mathrm{~m}$ away from the river.

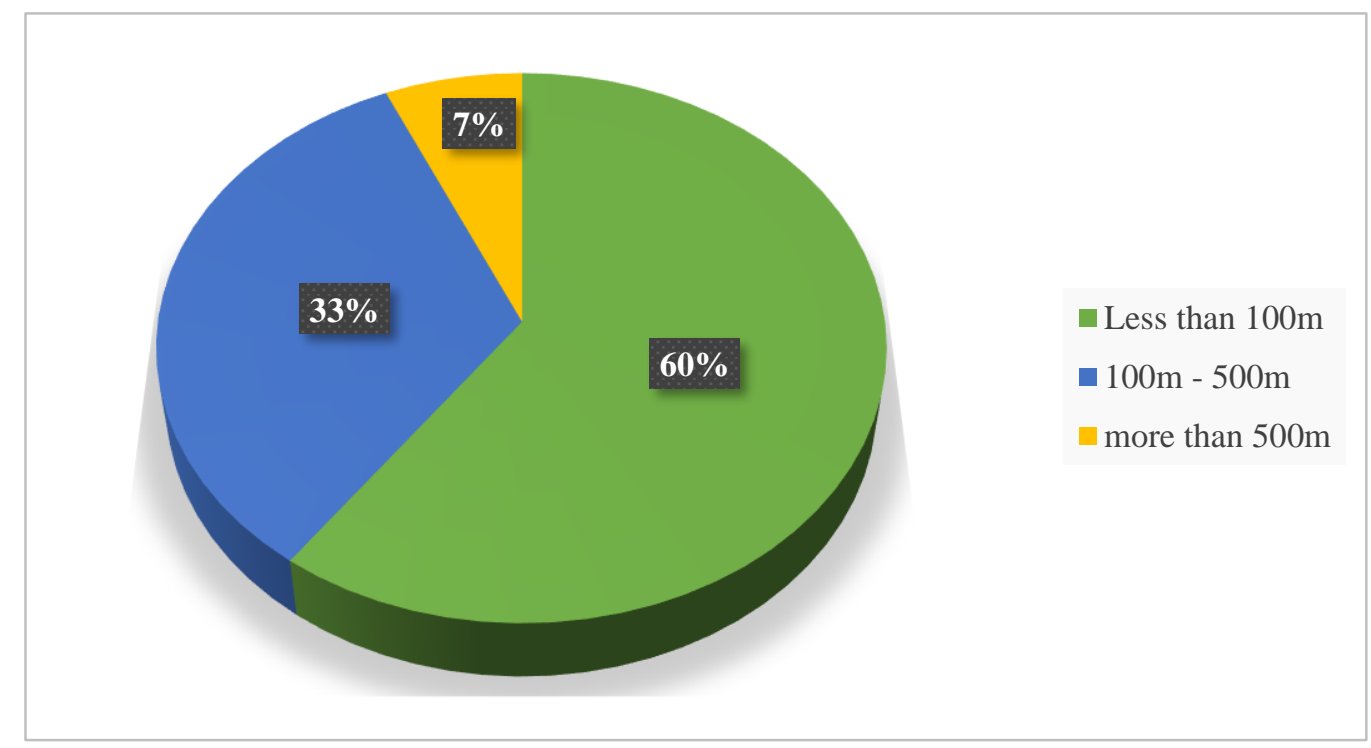

Source: Survey data, 2020

Figure 2. Location of houses according to the distance from the river 


\section{Land extents of the affected houses}

Figure 3 indicates that, majority of the affected houses (55\%) were built-up on 11 perches to 25 perches of land extent. Only $15 \%$ of house units were developed on more than 25 perches. Hence, $85 \%$ of the affected houses were built on less than 25 perches of land extent.

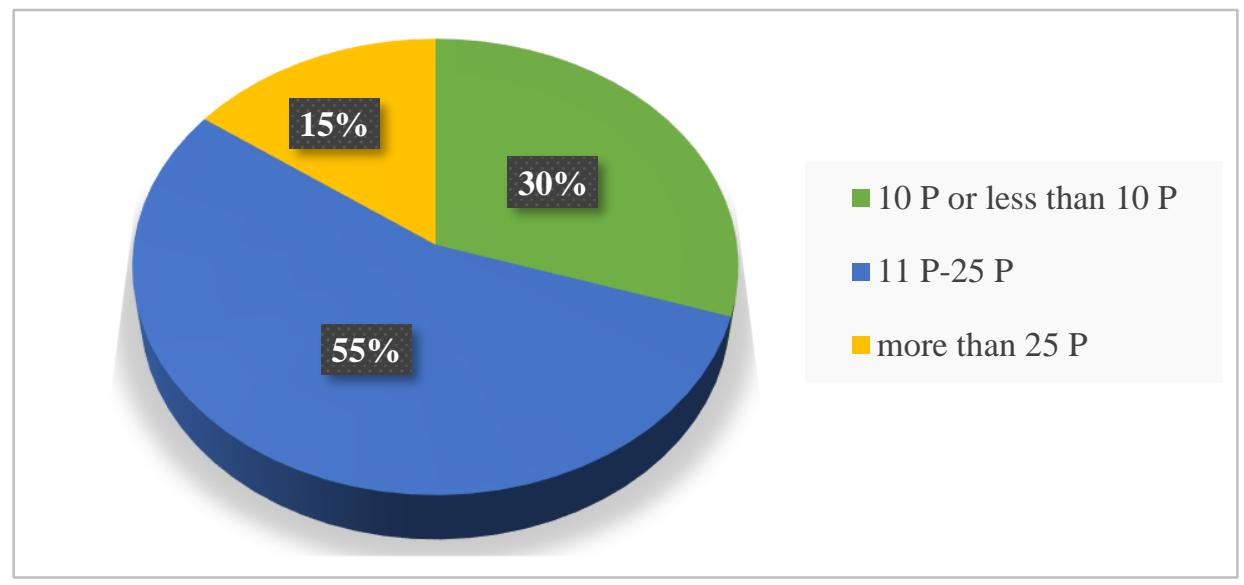

Source: Survey data, 2020

Figure 3. Plot size of the land

\section{Analysis of variables (both natural and man-made factors)}

As listed in Table 1, the study analyzed the perception on the flood causing factors under natural factors and man-made factors. These variables were assessed as per the mean values generated through the results of 5-point Likert scale questions in (Table 2).

Table 2 summarizes the descriptive statistics of the ten variables. Accordingly, lack of proper drainage system is the most significant flood causing factor followed by existing rules and regulations, heavy rain during especially in the first quarter of the year, issues with the physical characteristics of the lands and waste disposal in the area. The rest of the factors do not strongly influence for the flood risk in the study area. Compared to all the natural flood causing factors, man-made factors are the most influencing factors that increase the flood risk in Kelani River area.

Table 2. Descriptive statistics of natural and man-made flood causing factors

\begin{tabular}{|c|c|c|c|c|c|c|c|}
\hline Factor & Category & $\mathbf{N}$ & Minimum & Maximum & Sum & Mean & Std. Deviation \\
\hline Heavy rainfall & \multirow{5}{*}{$\begin{array}{l}\text { Natural } \\
\text { factors }\end{array}$} & 60 & 1 & 5 & 214 & 3.57 & .927 \\
\hline Wind & & 60 & 1.00 & 3.25 & 113.50 & 1.8917 & .39959 \\
\hline Land characteristics & & 60 & 1.00 & 4.00 & 151.50 & 2.5250 & .73747 \\
\hline River characteristics & & 60 & 1.00 & 5.80 & 96.20 & 1.6033 & .67647 \\
\hline Soil condition & & 60 & 1.00 & 3.00 & 104.50 & 1.7417 & .53076 \\
\hline Population increment & \multirow{6}{*}{$\begin{array}{l}\text { Man-made } \\
\text { factors }\end{array}$} & 60 & 1.00 & 3.00 & 94.00 & 1.5667 & .51845 \\
\hline Land use changes & & 60 & 1.00 & 3.25 & 101.75 & 1.6958 & .50019 \\
\hline Improper waste disposal & & 60 & 1.00 & 3.50 & 146.75 & 2.4458 & .54674 \\
\hline Lack of drainage system & & 60 & 3.25 & 5.00 & 271.50 & 4.5250 & .63729 \\
\hline Violation of regulations & & 60 & 1.75 & 5.00 & 231.25 & 3.8542 & .78017 \\
\hline Valid N (list wise) & & 60 & & & & & \\
\hline
\end{tabular}

Source: Survey data, 2020 
Out of all the natural flood causing factors, heavy rain especially first quarter of the year and the issues related to physical characteristics of land are the only two significant factors that create an influence to flood risk in the area (Table 2). During the heavy monsoon rains, low land areas including Kelani River area of Kaduwela MC Limits in Western Province are highly vulnerable for floods. This is because rainwater which flows down the river get congested in low land areas and once the water retention is exceeded the river water fills into low land areas. It can be observed that, most of the lands in the study area are low and undulated and highly exposed to floods. This can be aggravated during heavy rainy seasons.

Accordingly, the man-made factors that affected for flooding; lack of proper drainage system is the most significant factor that increases the flood risk in the area. There is no proper mechanism to minimize congesting water in low land area and to divert them to water ways or floodplains. People must live in alternative places until the water get dehydrated or went off from their lands. Sustainable drainage systems can regulate the flow and transport the water out of land areas. Also, the water retention capacity and the drainage are limited due to filling up floodplain areas, wetlands, and forests. These spaces and areas restore the flood water that comes to the land areas. When these are filled and developed for construction the natural drainage is interrupted.

Further, violation of prevailing rules and regulations and malpractices of people when comes to waste disposal have also become considerable flood causing factors in the area. The rules and regulations that imposed to minimize the flood risk in the area are not fully practiced by the people. Also, people do not have a proper waste disposal mechanism. They dispose them in to surrounding areas, abundant lands, floodplains etc. As a result, the waste gets stuck in drainages and minimize the flood retention and regular flow of water.

These man-made factors can be considered as major flood causing factors whereas the existing land use change with the population increment were found as minor flood causing factors. A similar process may be seen between the decline of vegetation area and the favorable trend of wide-spread built-up area. This is since the built-up area expanded considerably in 2018 from 10. $6 \%$. However, the change of land uses due to the population increment was not adversely affect for the flooding in the according to the descriptive statistical analysis findings, can be illustrated in graphically by using map. The land uses of Kaduwela Municipal Council area with the flood affected are interpreted as follows (see Figure 4).

\section{Analysis of expert opinions on flood causing factors using AHP method}

The views/opinions collected from the point of few experts via interviews analyzed through qualitative Analytic Hierarchy Process (AHP). The experts participated for the interviews were Grama Niladari (village level administrative officer, member of Kaduwela Municipal Council (disaster section), President of the Trade Union in the area and some selected residents who were living for more than 30 years in the area. As per the experts' responses, the author identified that there were nine major flood causing factors in Kelani River Area. The flood causing factors identification via experts' views were represented in Table 3. 


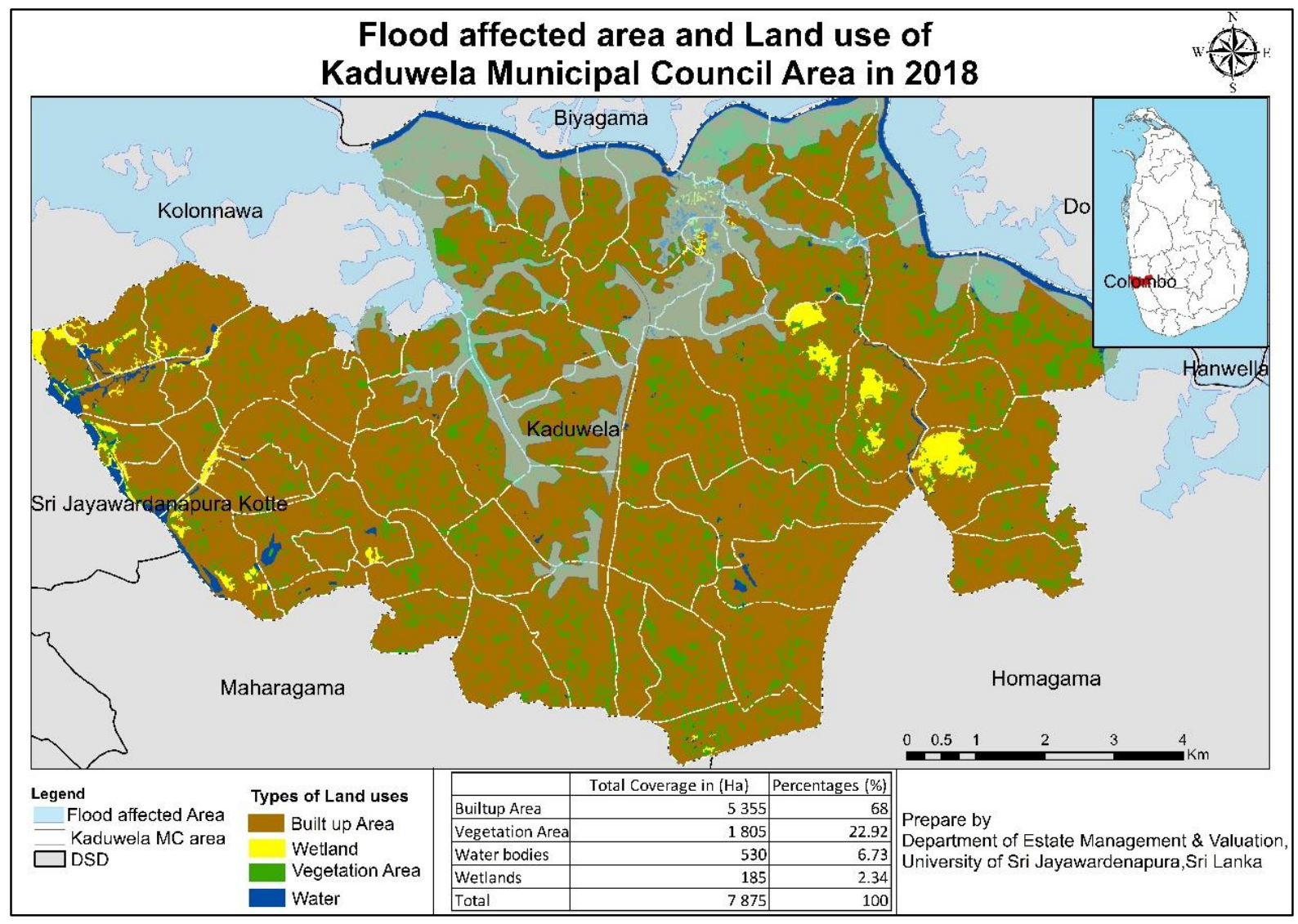

Source: Literature review data, 2020

Figure 4. Flood affecting area with land use of Kaduwela MC Area.

Table 3. Flood causing factor identification via experts' views.

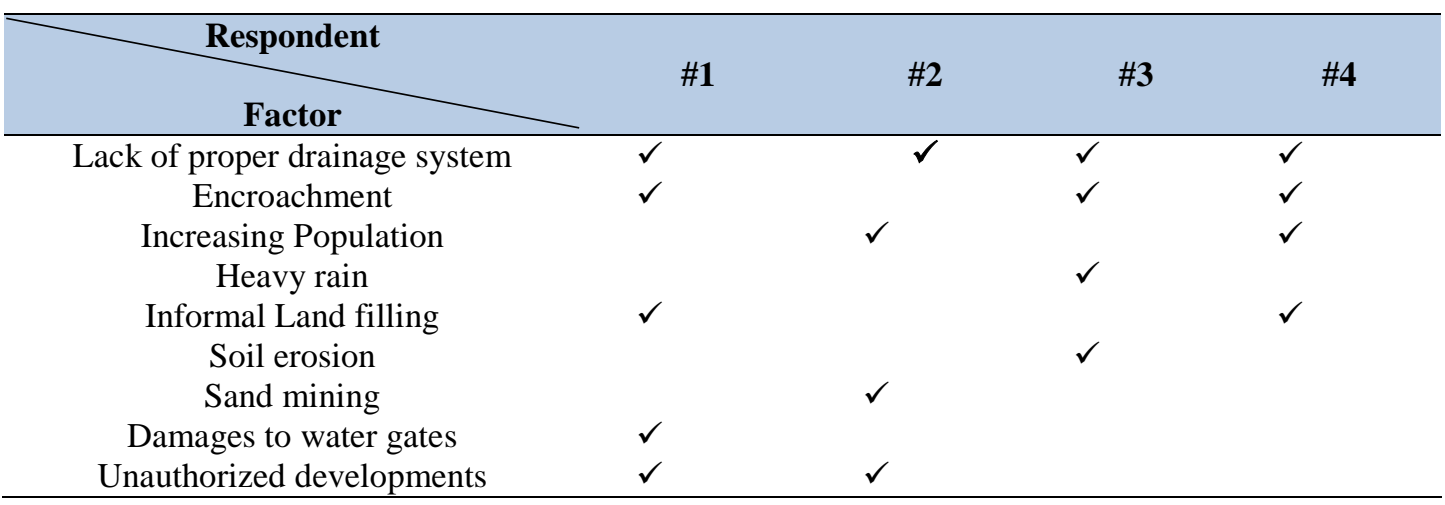

Source: Survey data, 2020

AHP analytical technique used for prioritizing the identified nine major flood causing factors from the experts' ideas. Accordingly, the Consistency Ratio (CR) is the most important aspect of AHP method, was examined the consistency of the expertise subjective judgment over the flood affecting factors. The inconsistency is acceptable, if the value of the Consistency Ratio 
is less than or equal to (0.10). If the Consistency Ratio is more than 0.10 , the subjective assessment must be revised. As per the table 4, CR value was in the acceptable level.

Table 4. Summary of AHP findings

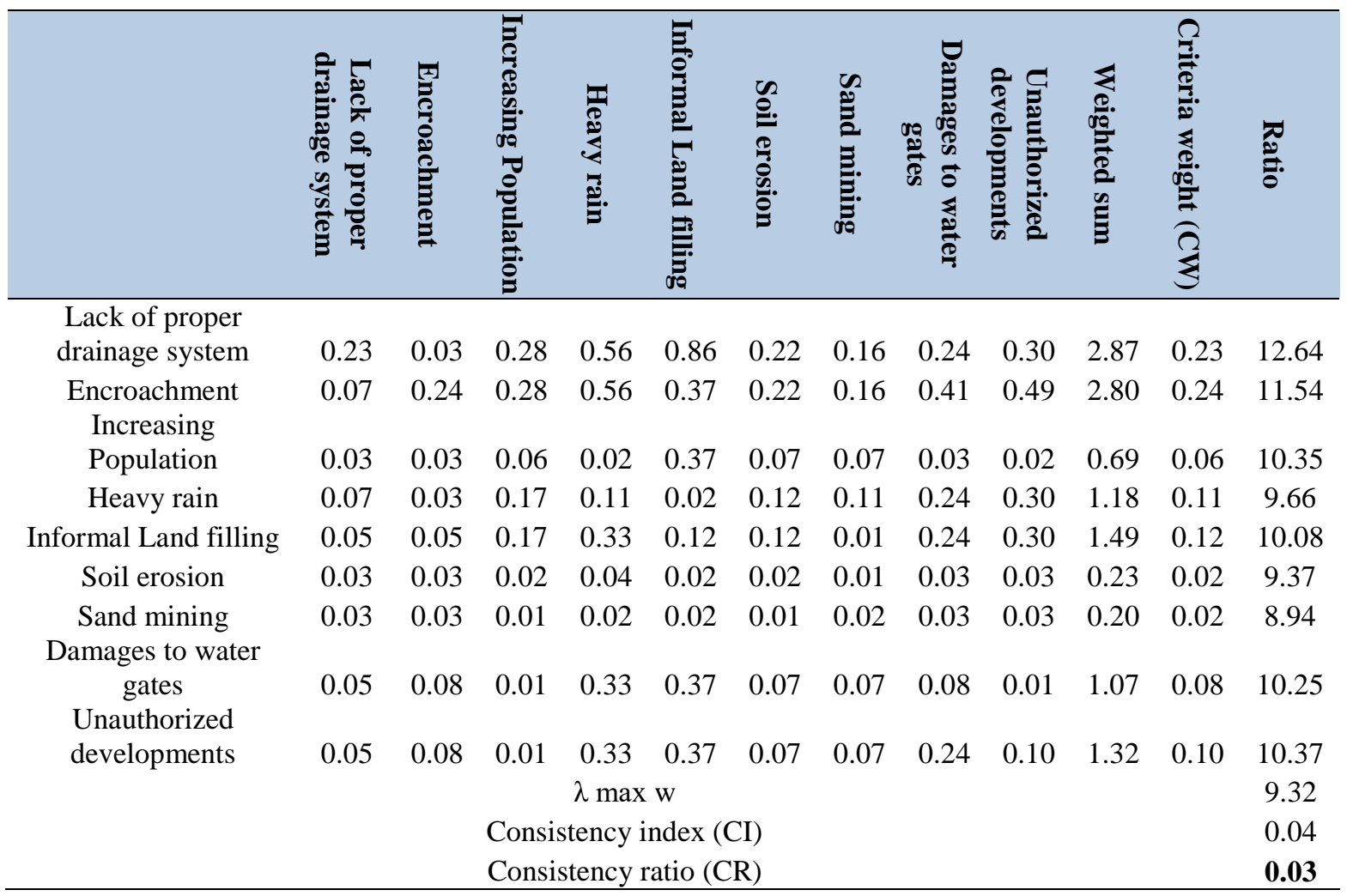

Source: Survey data, 2020

The Criteria Weights (CW) identified the prioritized significant flood producing variables in the research region based on the acceptable CR. Accordingly, "encroachment" and "lack of proper drainage system" have CW values of 0.24 and 0.23 respectively (Table 4), the most addressed flood causing factors in the study area. As the result, storm water abnormally collected due to heavy rain get blocked in the city limits without having proper drainage system. This situation gets aggravated when there is an overflow of water from the river. Consequently, collected water automatically flows to low level areas around the city limits. The natural drainage of the area has already been damaged by encroachments. As per the findings, encroachments can be clearly seen sides of the riverbanks violating the regulation of minimum distance from the river. Most of the residents in the area lived within 100m of the Kelani River. Consequently, these human settlements constructions in riverbanks destroy the plantation along the river boundaries loosening the soil condition, hence, increases the flood risk. Further, CW values of informal land filling $(0.12)$ and unauthorized developments $(0.10)$ respectively significant flood causing factors.

Consequently, people intend to unauthorized developments due to land supply is limited within Kaduwela MC Area. It is significant that many commercial, industrial, and the residential buildings have constructed closer to the river. Marshy lands, paddy fields and natural flood prone areas were filled and used for developments. High rise commercial and residential buildings as a trend are being constructed on those filled lands. These spaces previously used to absorb the water coming into land areas. Unauthorized filling of these swampy lands and using those lands for 
developments increase the time of water retaining in the surrounding areas. Also, damages of water gates $(\mathrm{CW}=0.08)$ is another flood causing factor in the area. Watergates (floodgate) were previously set to auto function when water level is increased. The excess water gradually flows to the paddy fields and directed water bodies later and systematically reflow to the river within shorter period. However, these Watergates are currently damaged and are not functioning. As a result, water flows with no control and flocked in the area for a longer period. Other than these manmade flood causes, heavy rain to up country is a reason for outflow of Kelani River, CW value of 0.11. However, the main issue in this case is that, owing to a lack of appropriate drainage, it takes a long time to send overflowed water to waterways.

As a result, the qualitative findings of the study support the quantitative findings of the study, which showed that the most important flood-causing factors in the area are man-made factors rather than natural factors. Both analysis revealed that flooding in the area was caused by man-made factors such as a lack of proper drainage, violations of regulations, ineffective waste disposal, and informal land filling, as well as the natural causative factor of heavy rainfall. The results are in par with some of the findings, respectively such as the blockage of drainage system with the findings of Cirella et al., 2019, Nigeria, and improper waste dumping, encroachment of riverbanks with Eran \& Worku, 2018 in Ethiopia and with Ijaz et al., 2021 in Pakistan, as well as the natural causative factors like heavy rainfall with Cirella et al., 2019, in Nigeria.

\section{Conclusion}

Kaduwela Municipal Council limits located in Colombo Administrative District is observed as a major flood risk area in the country where one of the major rivers called Kelani runs through. During past decade, the frequency of flood events in this area has increased due to several factors. The study explores to identify the significantly contributing factors on flood. The findings obtained from both analysis methods concluded that man-made factors are the most influenced factors for flooding in this area. Findings from residents' perceptions emphasize that non-availability of proper drainage system, violating rules and regulations, ineffective waste disposal are the major man-made flood causing factors in the area. Results of the AHP analysis that contained the views of the experts, further justified that the same above results such as the non-availability of proper drainage system as well as encroachments, increasing population, informal land filling, unauthorized developments, and no attentions on the maintenance of broken Watergates are some other direct and indirect man-made flood causing factors.

However, the Kelani River Area gets inundated with swiftly followed by the highlighted man- made factors rather than natural factors. Therefore, this study encourages the immediate attention to construct and maintain proper drainage system as an inevitable factor though it takes time. Improving the positive attitude of the people to ban the unauthorized actions is also encourage at the same time collaboratively by the responsible institutions and the leaders of the societies in the area. Improper waste disposal, unauthorized developments, and sand mining in the area should be strongly regulated as supportive factors to minimize the flood risk.

\section{Acknowledgement}

Authors would like to acknowledge the Center for Real Estate Studies (CRES), Department of Estate Management and Valuation, University of Sri Jayewardenepura, Sri Lanka. 


\section{References}

Alfieri, L., Bisselink, B., Dottori, F., Naumann, G., Roo, A. D., Salamon, P., \& Feyen, L. (2017). Global projections of river flood risk in a warmer world. Earth's Future, 5, 171-182.

Al-Juaidi , A., Nassar, A., \& Al-Juaidi, O. (2018). Evaluation of flood susceptibility mapping using logistic regression and GIS conditioning factors. Arabian Journal of Geoscinences, 11. doi:https://doi.org/10.1007/s12517-018-4095-0

Bouwer, L. M., Crompton, R. P., Faust, E., Hoppe, P., \& Pielke, R. (2007). Confronting disaster losses. Science, 318, 753. doi:10.1126/science. 1149628

Brauch, H. (2003). Urbanization and natural disasters in the Mediterranean: Population growth and climate change in the 21 st century. In A. Kreimer, M. Arnold, \& A. Carlin (Eds.), Building safer cities: The future of disaster risk. The World Bank.

Centre for Research on the Epidemiology of Disasters (CRED). (2020). Natural disasters 2019. https://reliefweb.int/sites/reliefweb.int/files/resources/ND19.pdf

Chan, N. W. (1997). Increasing flood risk in Malaysia: Causes and solutions. Disaster Prevention and Management, 6(2), 72-86.

Cirella, G. T., Iyalomhe, F. O., \& Adekola, P. O. (2019). Determinants of flooding and strategies for mitigation: Two-year case study of Benin city. Geosciences, 9, 1-15.

Disaster Management Centre. (2017). Rapid impact assessment report. Colombo: Disaster Managment Centre.

EM-DAT. (2009). General classification. Retrieved from https://www.emdat.be/classification

Erena, S. H., \& Worku, H. (2018). Flood risk analysis: Causes and landscape based mitigation strategies in Dire Dawa city, Ethiopia. Geoenvironmental Disasters,5(16), 1-19.

Farley, J. M., Suraweera, I., Perera, W., Hess, J., \& Ebi, K. L. (2017). Evaluation of flood preparedness in government healthcare facilities in Eastern Province, Sri Lanka. Global Health Action, 10(1), 1-11. doi:10.1080/16549716.2017.1331539

GRID-Arendal. (2006). Trends in natural disasters. Retrieved from https://www.grida.no/resources/7795

Hadipour, V., Vafaie, F., \& Deilami, K. (2020). Coastal flooding risk assessment using a GISbased spatial multi-criteria decision analysis approach. Water, 12, 1-18.

Hettiarachchi, P. (2020). Hydrological report on the Kelani River flood in May 2016. https://www.researchgate.net/publication/342865359_Hydrological_Report_on_the_Kela ni_River_Flood_in_May_2016

Hoeppe, P. (2016). Trends in weather related disasters-Consequences for insurers and society. Weather and Climate Extremes, 11, 70-79. doi:http://dx.doi.org/10.1016/ j.wace.2015.10.002

Ijaz, S., Miandad, M., Mehdi, S., Anwar, M., \& Rahman, G. (2021). Solid waste management as a response to urban flood risk in Gujrat city, Pakistan. Malaysian Journal of Society and Space, 17(1), 1-13. https://doi.org/10.17576/geo-2021-1701-01

Japan International Cooperation Agency (JICA). (2017). Data collection survey on desaster risk reduction sector in Sri Lanka; Final report. Retrieved from https://openjicareport.jica.go.jp/216/216/216_120_12291944.html

Khan, S. I., Hong, Y., Wang, J., Yilmaz, K. K., Gourley, J. J., Adler, R. F., \& Irwin, D. (2010). Satellite remote sensing and hydrologic modeling for flood inundation mapping in Lake Victoria basin: Implications for hydrologic prediction in ungauged basins. IEEE Transactions on Geoscience and Remote Sensing, 49(1), 85-95. 
Kron, W. (2009). Flood insurance: From clients to global financial markets. Journal of Flood Risk Management, 2, 68-75. doi:10.1111/j.1753-318X.2008.01015.x

Ministry of Disaster Management. (2016). Sri Lanka post disaster need assessment, floods and landslide May 2016. Colombo: Ministry of Disaster Management.

Ministry of Irrigation and Water Resources Management. (2018). Strategic environmental assessment of development of river basin level flood and drought mitigation investment plans-Kelani river basin. http://crip.lk/wp-content/uploads/2019/01/Kelani-River-SEAStudy-Final-Report.pdf

Shao, W., Li, Y., Yan, D., Liu, J., Yang, Z., \& Yang, Z. (2019). Analysis of the losses due to flood and waterlogging disasters in China during 2006 to 2017. Proceedings, 7. doi:10.3390/ECWS-3-05820

Stoffel, M., Bollschweiler , M., Butler , D., \& Luckman , B. (2010). Tree rings and natural hazards: An introduction. Retrieved from https://www.researchgate.net/publication/ 283600734_Tree_Rings_and_Natural_Hazards_An_Introduction

Surasinghe, T., Kariyawasam, R., Sudasinghe, H., \& Karunarathna, S. (2020). Challenges in biodiversity conservation in a highly modified tropical river basin in Sri Lanka. Water, 12(1), 1-25.

Svetlana, D., Radovan, D., \& Ján, D. (2015). The economic impact of floods and their importance in different regions of the world with emphasis on Europe. Procedia Economics and Finance, 34, 649-655.

WHO. (2021). Floods - Technical Hazard Sheet - Natural Disaster Profile. Retrieved from https://www.who.int/hac/techguidance/ems/floods/en/

WHO/EHA. (2002). Disasters and emergencies. Retrieved from https://apps.who.int/disasters/repo/7656.pdf

Zhou, L., Wu, X., Xu, Z., \& Fujita, H. (2017). Emergency decision making for natural disasters: An overview. International Journal of Disaster Risk Reduction, 27, 567-576. doi:http://dx.doi.org/10.1016/j.ijdrr.2017.09.037 